\title{
Realization of a Smart Aquaponics System: A Closed - Loop System
}

\author{
Kushal $\mathbf{S}^{\mathbf{1}}$, Honnu $\mathbf{S}^{2}$, Sindhu $\mathbf{R}^{3}$ \\ MCA, The Oxford Engineering College, Bangalore, India ${ }^{1}$ \\ Student, BE, Department of ISE, BIT, Bangalore, India ${ }^{2}$ \\ Student, BE, Department of CSE, VTU, Belgaum, India $^{3}$
}

\begin{abstract}
The word Aquaponics can be split into two words, aquaculture and hydroponics. Hydroponics includes growing plants in Coco peats instead of soil. Aquaculture involves fish cultivation by providing the necessary support system for a good yield. Aquaponics is a closed loop system and an ideal organic design. The system sustains by itself and doesn't involve the use of harmful chemicals like pesticide, fungicide or insecticide. In this paper we put in efforts to develop a smart Aquaponics system capable of self-monitoring and reflex. The system employs sensors to measure the $\mathrm{pH}$, temperature and water level which are the essential inputs to the IoT prototype that we have built. A Wi-Fi module is used to transmit the sensed data in real time, and to trigger essential reflex at various instances. Data received from the sensors are uploaded to blynk cloud, an IoT cloud platform that uses real-time information to analyse and visualize data. The need for mobility of the system was recognized and the system made portable and robust using minimum electronic units and minimum power requirement.
\end{abstract}

Keywords: Aquaponics, Closed Loop System, Self - Monitoring and Real Time Monitoring, Trigger Essential Reflex at Instants

\section{INTRODUCTION}

Aquaponics is a self-sustained agricultural technique combined with fish cultivation. [1] It is the best example of a selfsustained closed loop system practised around the world. Aquaponics is the future of food production and fish cultivation. Fish waste or excreta mainly ammonia is converted to plant nutrients by bacteria. This eliminates the need for chemical nutrients which may be harmful to the plant, soil or the consumer. The concept of closed loop is brought about by intelligent electronic units and is automated. In this assignment we have analysed six types of data, which are the main parameters to differentiate between traditional Aquaponics (existing system) and Smart Aquaponics (proposed system).

1. Cost comparison.

2. Average height of the plant / size of the yield.

3. Water consumption.

4. Water quality for both fishes and plants.

5. $\mathrm{pH}$ value and temperature analysis.

6. Use of chemical fertilizers, pesticides and insecticides.

\section{PROPOSED SYSTEM}

Our objective is to develop a self-sustainable, closed loop, automated and portable Aquaponics system capable of realtime temperature, $\mathrm{pH}$ and water level sensing. The system through threshold values initiates necessary reflexes as follows: [2]

1. Pumping in water to the fish tank (from external source or from the plants).

2. Pumping water to the plants.

3. Feeding the fish frequently.

4. Temperature regulation.

The data/ information regarding the system obtained through the sensor and stored in the cloud is continuously analysed to obtain conclusions and to compare with the yield of the traditional system. 
Vol. 8, Issue 5, May 2019

\section{SYSTEM REQUIREMENTS}

\section{A. Functional Requirements}

Functional requirements define the functionality of a system to be developed. It also reflects the functionality of the user in the system. The functional requirements of the proposed system are

1. A sophisticated feedback control system to pump the water to and fro within the closed loop. [3]

2. Efficient sensing unit consuming less power and accurate as per industrial standards.

3. Reliable connectivity between the sensing unit and the cloud.

4. An effective algorithm or system to compare the yield of traditional and proposed system.

5. Fine calibration to keep up with the standards.

6. Placing experimental threshold for apt real-time reflexes.

B. Non-functional Requirements

Non-functional requirements play the behaviour and performance of the system at its critical stages

1. Extra amount of water to cope up with the evaporative losses from the plant due to transpiration.

2. Suitable number of I/O ports to accommodate extra sensing elements when required.

3. Provision of adding new links and expanding the network in case of saturation.

4. A buffer to enrich processing at critical stages.

5. Accommodating new load with minimum power consumption.

\section{METHODOLOGY}

1. Closed loop water pumping- we have followed a closed loop reflexive system wherein water is pumped to the plant from the fish tank and back. The fish excreta are a source of nutrient for the plants. A servo motor conditionally regulates water in the closed loop system. The guiding parameters for regulation are the data from the sensors. Threshold placed guides the system to carryout suitable reflexes.

2. Fish feeding- the system is automated to feed the fish frequently and sufficiently. The health and well-being of the fishes in the system directly affects the yield of the plants.

3. Analysis- the data stored in the cloud helps in comparing the yield of the smart Aquaponics to that of the traditional system's yield. Table 1 shows the difference between Aquaponics technique and the traditional farming technique. This analysis is crucial for the technical fraternity to measure the success of the model.

\section{SYSTEM DESIGN}

Figure 1 shows the proposed system of a closed loop Aquaponics system. The plants are mounted on the coco peats, and are placed in growing beds filled with water pumped in from the fish tank (use of servo motors) containing nutrients which have been synthesized by the bacteria. The water is fed back to the fish tank when required. Water level detectors monitor the water levels in the system continuously for proper water regulation for both plants and fishes. The $\mathrm{pH}$ sensors indicate the acidity of water, for proper plant and fish health. The temperature sensors are essential to maintain ideal temperature for good yield of both fish and plant. The temperature regulator regulates the effective temperature of the system for a balanced ecosystem. Wi-Fi module is used to transmit the data to the cloud for analysis and troubleshooting. [4] Figure 2 shows the schematic diagram of the prototype.

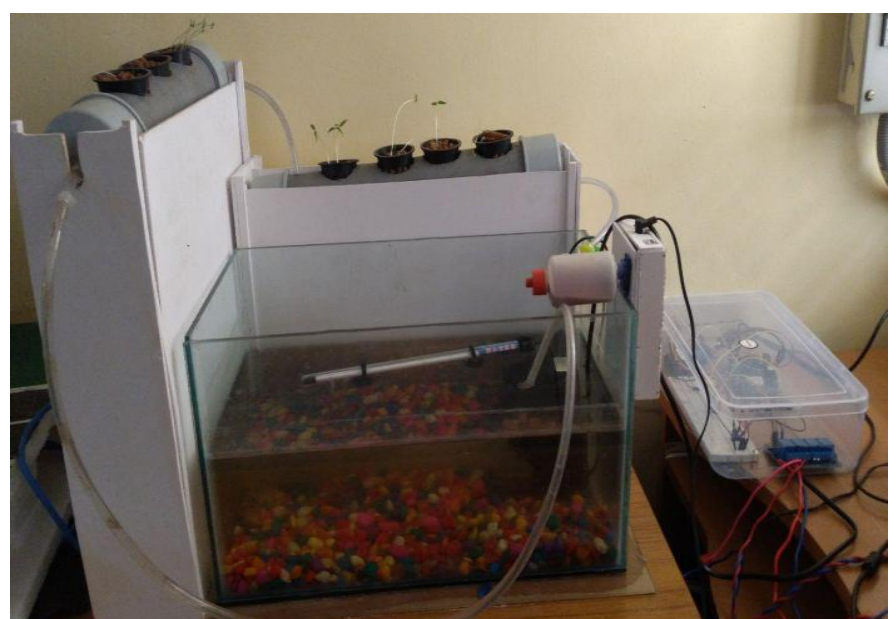

Figure 1 shows the proposed system of a closed loop Aquaponics system. 


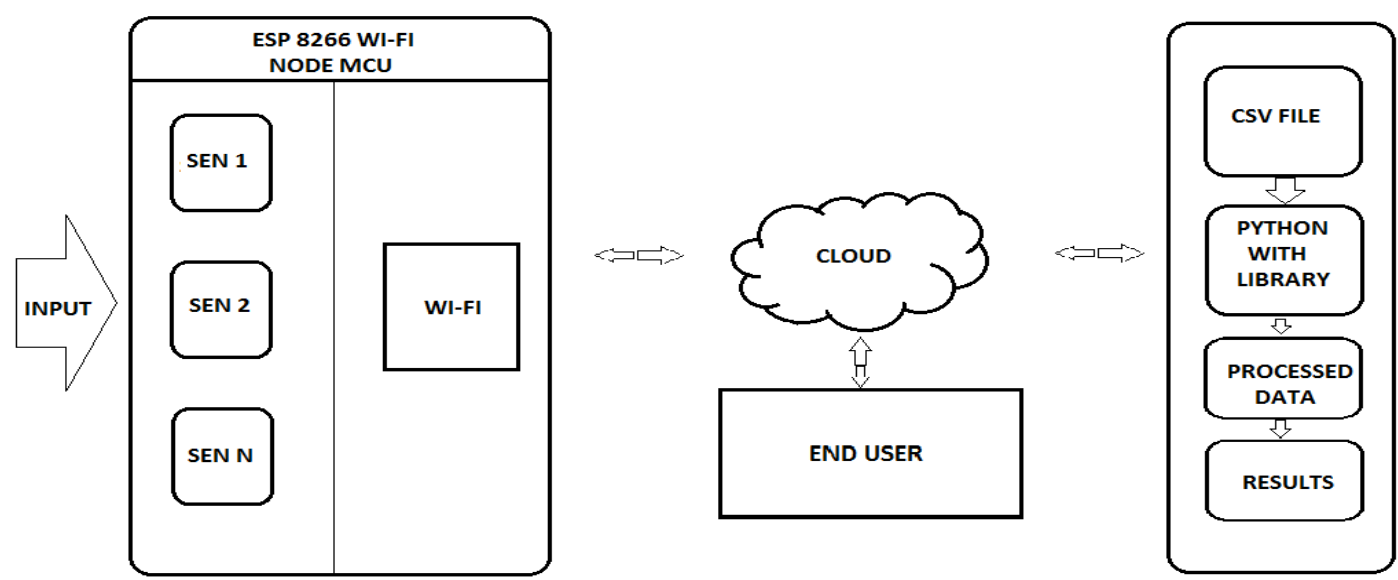

Figure 2 shows the schematic diagram of the prototype.

\section{RESULTS}

1. $\mathrm{pH}$ value analysis

Fishes stay healthy between the $\mathrm{pH}$ range of 5 to 10 . Plants need a $\mathrm{pH}$ value less than 6.5. Since, our system is a closed loop ecosystem existing and dependent on each other a $\mathrm{pH}$ range of 6-7 is acceptable.

2. Temperature analysis

- Average temperature data of a particular day is as shown in figure 3.

- Temperature analysis on hourly basis on a particular day is shown in figure 4.

3. Growth analysis

Table 1 shows the comparison between the yield produced by the traditional and the smart Aquaponics system.

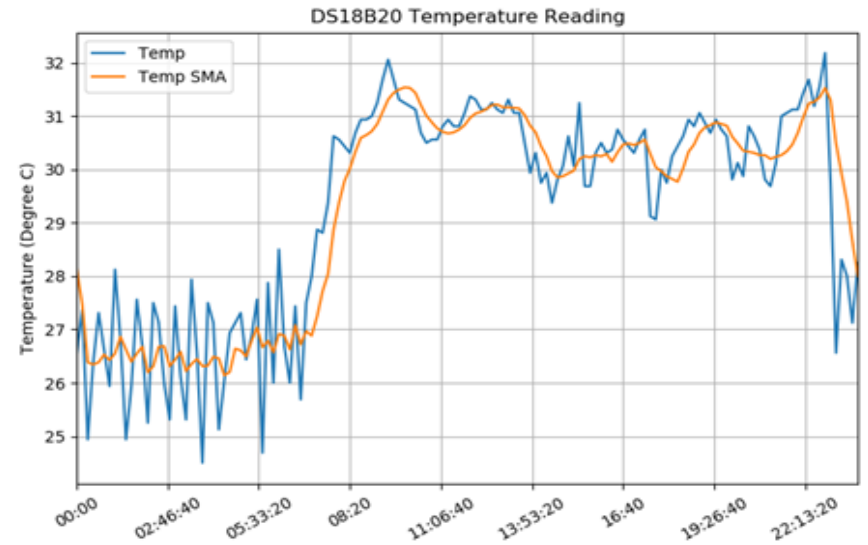

Figure 3 shows the average temperature data of a particular day.

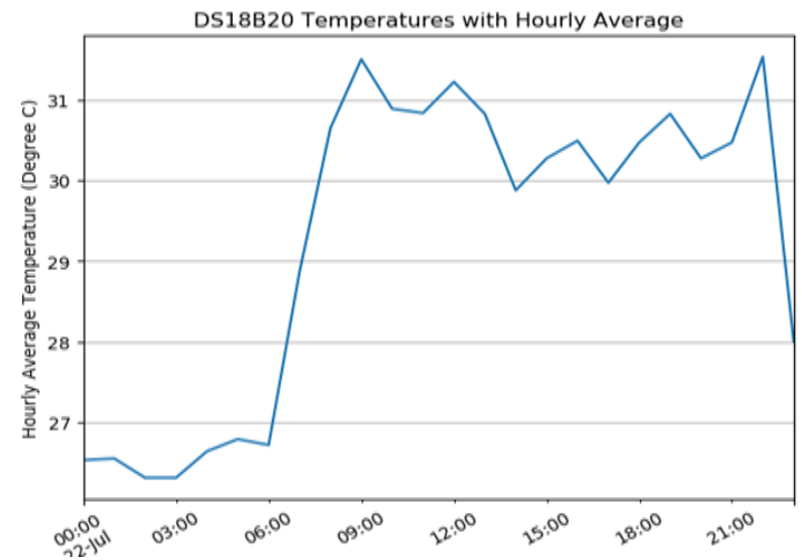

Figure 4 shows the temperature analysis on hourly basis on a particular day. 
Table 1 shows the comparison between the yield produced by the traditional and the smart Aquaponics system.

\begin{tabular}{|c|c|c|}
\hline $\begin{array}{c}\text { No. of } \\
\text { days after } \\
\text { planting } \\
\end{array}$ & $\begin{array}{c}\text { Smart Aquaponics } \\
\text { Technique }\end{array}$ & Traditional farming \\
\hline 7th day & & \\
\hline 30th day & & \\
\hline 90th day & & \\
\hline 105th day & & \\
\hline 110th day & & \\
\hline
\end{tabular}

\section{CONCLUSION}

From the results obtained we can quote that smart and portable Aquaponics is the need of the day. Our system automates the traditional system by intelligent reflexes. Threshold fixed can be changed can be resulting in better handling/ controlling of the system. This initiation is essential in case of varying environmental factors and forced changes to be made in the system. This system is by itself a self-sustaining smart and chemical free (organic) agricultural technique. This proposed system has the capability to set new standards in agriculture and fish cultivation. A balanced eco-system combined with automation and human inputs can transform the global agricultural scenario. A better yield would indicate better profit making and sufficient resources to feed the global population.

\section{REFERENCES}

[1]. Aquaponics Guidelines- DOI: 10.13140/RG.2.1.4975.6880

[2]. A better way of farming: building an Aquaponics system in the classroom- DOI: 10.2505/4/tst18_086_03_40

[3]. Chandraprakash Patidar, "E-IRRIGATION: An Automation of Irrigation using Wireless Networks", Journal (IJSRNSC), Vol. 1, Issue. 5, pp.18-20, Nov-2013.

[4]. Megumi U. Leatherbury, Department of Engineering Technology, "VEGILAB and Aquaponics Indoor Growing System", Weber State University. 2014 IEEE Conference on technologies for Sustainability- $20164^{\text {th }}$ International Conference on Future Internet of Things and Cloud Workshops. 